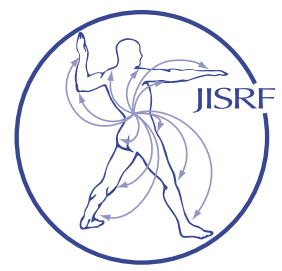

\title{
Intrapelvic Pseudotumor Causing Neuropathy and Vascular Obstruction After Revision Total Hip Arthroplasty: A Case Report
}

Sweet, $M^{1}$; Snoap, $T^{2} ;$ Roehr, $B^{2} ;$ Roberts, $J^{2}$

\section{Abstact}

Background: There is a growing body of recent literature regarding the occurrence of pseudotumors associated with modular junctions and various bearing surfaces after total hip arthroplasty (THA). Revision surgery is often technically challenging and high complication rates have been reported. The optimal management of these patients and outcomes after operative treatment remain poorly understood.

Methods: We report the case of a 77-year-old male with progressive unilateral lower extremity swelling, pain, and neuropathy 9 years after revision THA for polyethylene liner wear. Imaging and biopsy confirmed a massive intrapelvic pseudotumor exerting compressive effects. Radiographs demonstrated extensive femoral and pelvic osteolysis without evidence of component loosening. Debulking of the intrapelvic portion of the pseudotumor was performed via the lateral window of the ilioinguinal approach with component retention.

Results: Debulking of the intrapelvic mass resulted in resolution of symptoms. One year postoperatively the patient reported pain free ambulation using a walker and no recurrence of symptoms. Radiographs demonstrated stable THA components in comparison with preoperative films.

Discussion and Conclusion: This case demonstrates a rare finding of intrapelvic pseudotumor causing neurovascular compression after revision THA. Clinicians should be aware of intrapelvic pseudotumor as a possible cause of limb swelling and neuropathy, and that debulking of the mass is a potential treatment option in the setting of wellfixed implants.

\section{Background}

Adverse local tissue reaction (ALTR) is being increasingly encountered in the setting of failed total hip arthroplasty (THA). Recent literature has focused on increasing our understanding of the biologic mechanisms that induce ALTR, as well as summarizing available evidence regarding the diagnosis and management of patients with this problem, which is recognized to lead to poorer outcomes [1-4]. Briefly, ALTR is a pathological biological tissue response that occurs in association with a joint replacement resulting from chronic immune response to wear debris. ALTRs include variable amounts of osteolysis, tissue necrosis, fluid collection, and soft tissue masses. 'Pseudotumors' are a form of ALTR, referring to benign, aseptic soft tissue masses which develop in the vicinity of a THA, and may be cystic, solid, or both [4-7]. The term pseudotumor is commonly used in reference to metal-on-metal

Keywords: Pseudotumor; Total Hip Arthroplasty; THA; Pelvic Mass; Adverse Local Tissue Reaction; Femoral Nerve Neuropathy Level of Evidence: IV 
(MoM) THA, however, these masses have been associated with various types of THA bearing surfaces $[\underline{1}, \underline{4}, \underline{\underline{8}}, \underline{8}-\underline{11}]$. Pseudotumors most commonly present in the periarticular tissues and can be asymptomatic or may be a source of chronic pain due to soft tissue destruction or compressive effects. Here, we report the case of a patient with a large symptomatic pseudotumor with both intrapelvic and extrapelvic components after revision THA. The intrapelvic component resulted in vascular obstruction and femoral neuropathy, which successfully resolved after debulking of the mass. The patient was informed that his case would be submitted for publication, and he provided consent.

\section{Case Presentation}

A 77-year-old male was referred to our institution for evaluation of right lower extremity edema, neuropathy, and pain associated with a right pelvic mass. The patient had previously undergone a ceramic-on-polyethylene primary THA in 1992 with a DePuy AML cementless femoral stem, ceramic femoral head, and Duraloc acetabular cup with a Hylamer liner (DePuy Orthopaedics Inc, Warsaw, IN). This was subsequently revised in 2010 by head and liner exchange for polyethylene wear and osteolysis. The acetabular liner was replaced with a Duraloc Marathon polyethylene acetabular liner (10 degree, $+4 \mathrm{~mm}$ offset, $36 \mathrm{~mm}$ inner diameter, 56/68 mm outer diameter) and the ceramic head was revised to an M-Spec metal femoral head (36 mm diameter, 14/16 taper, +0 offset; DePuy Orthopaedics Inc, Warsaw, IN). Both the index and revision THAs were performed at outside institutions. He had no history of prosthetic joint infection.

The patient had a medical history of well-controlled diabetes mellitus (HbAlc <6.0), peripheral vascular disease, and atrial fibrillation managed with Coumadin. His pertinent surgical history included a right femoral-peroneal in-situ bypass graft, right L3-4 laminectomy, both within three years of presentation, and bilateral THAs. His body mass index was $26.9 \mathrm{~kg} / \mathrm{m}^{2}$ and he ambulated functional distances using a walker.

In early 2019, the patient began experiencing worsening buttock and groin pain, anterior thigh paresthesias, and diffuse swelling in the right lower extremity. His initial workup for radiculopathy was performed by his neurosurgeon. An MRI of the lumbar spine obtained incidentally revealed a large right-sided pelvic mass (Fig. 1). A computed tomography (CT) scan demonstrated a heterogenous mass in the right hemipelvis which measured approximately 13 x $10 \times 26 \mathrm{~cm}$ in dimension (Fig. 2). A CT-guided biopsy was performed and revealed fibrinous and necrotic tissue

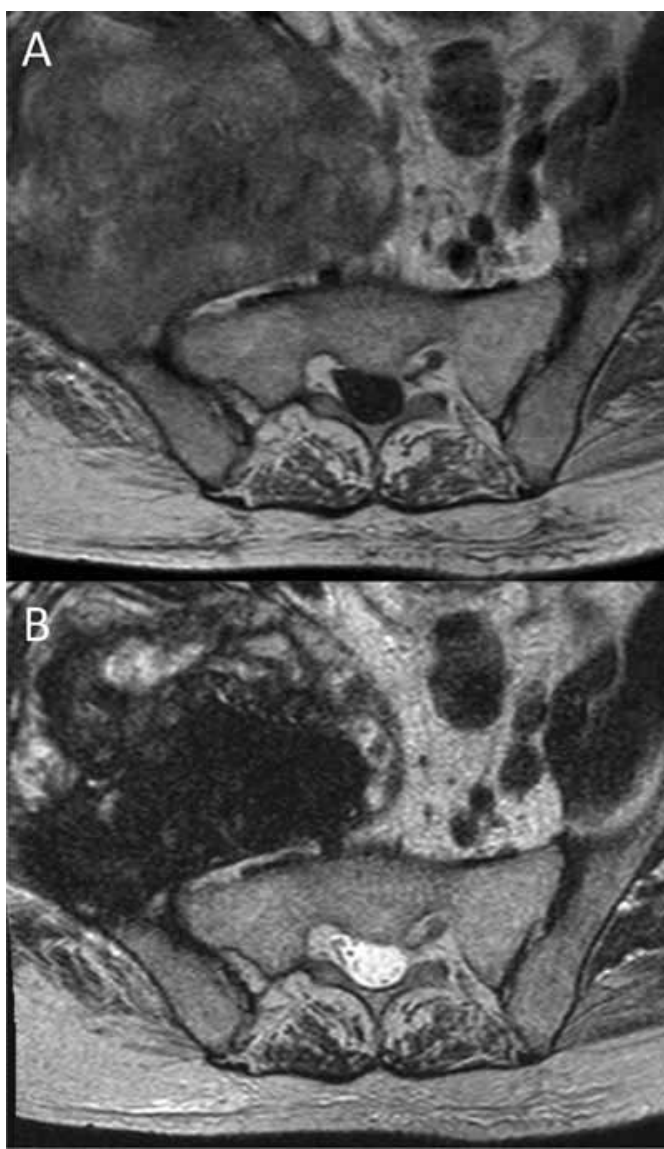

Figure 1:

Axial T1weighted

(Fig. 1-A) and

T2-weighted

(Fig. 1-B)

MRI images

of the pelvis

demonstrating

a large

heterogenous

mass in the

right iliac

fossa with

compression

of the pelvic

cavity.

with extensive histiocytic infiltrates and few foreign body giant cells. No organisms were cultured, no malignant cells were identified, and no metallic debris was seen. The patient was then referred to a regional academic medical center for evaluation by an orthopaedic oncologist. His case was presented at their multidisciplinary tumor board, and it was felt the mass was due to particulate disease related to his THA. He was then referred to our institution for definitive treatment.

Radiographs obtained during our initial evaluation demonstrated severe osteolysis involving both the proximal femur and acetabulum, with complete destruction of the superior pubic ramus (Fig. 3). The cementless stem and acetabular cup appeared well-fixed to bone with an intact superior rim and no obvious superior or medial migration of the cup. On physical examination, he had diffuse pitting edema throughout the right lower extremity to the thigh, and a mass-like fullness in the right gluteal region. He stated it felt as if he was "sitting on a tennis ball in the right hip." There was no palpable mass over the iliac crest.

The mass had become very debilitating to the patient, and his primary complaint was significant swelling in the right lower extremity. Preoperatively, multiple lengthy discussions were held with the patient and his family on separate occasions. His imaging was reviewed, and the risks, benefits, and alternatives to both operative and non-opera- 

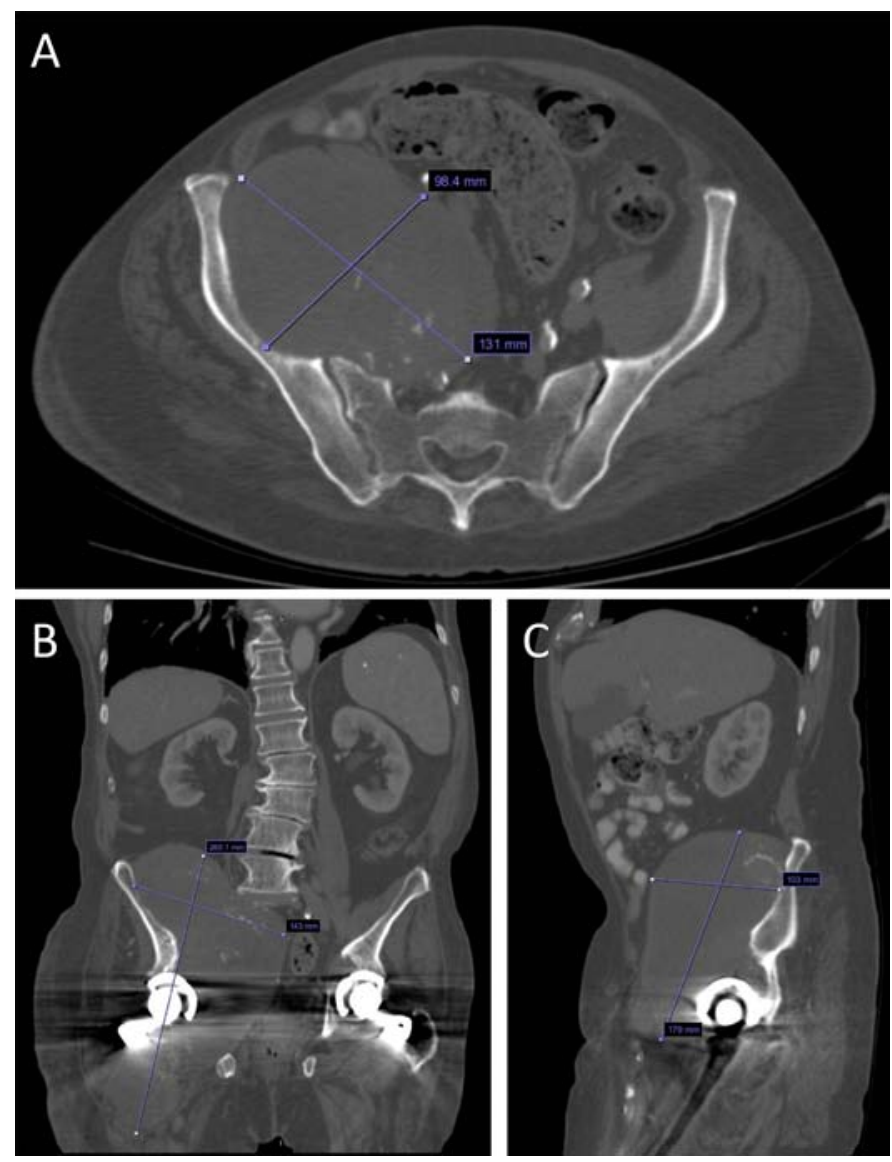

Figure 2: Preoperative axial (Fig. 2-A), coronal (Fig. 2-B), and sagittal (Fig. 2-C) CT images demonstrating a heterogenous destructive mass with scattered peripheral and internal calcification measuring approximately $13 \times 10 \times 26 \mathrm{~cm}$ in dimension involving the right hemipelvis from the iliac fossa to midline. The lesion is causing mass effect on the intrapelvic structures and envelops the right acetabulum and hip prosthesis, extending into the posterior musculature of the right thigh. The mass communicates through a region of extensive osteolysis in the superior pubic ramus to the periprosthetic area.

tive treatment were thoroughly discussed. The complexity of his diagnosis and surgical options were explained, including the risks of progression of his osteolysis and further bone loss making acetabular and femoral reconstruction more challenging than his current situation. Furthermore, his left THA, which also had significant radiographic osteolysis, was discussed. However, he was asymptomatic on the left side and deferred operative treatment. Ultimately, the patient clearly expressed his treatment goals, which entailed undergoing the least amount of surgery that could potentially alleviate some of his symptoms of swelling and paresthesia's. He had low functional demands and understood surgery would not be curative and there was a possibility of recurrence. After thorough discussion, he elected to proceed with debulking with the goal of relief of his compressive symptoms. Preoperatively, the decision was made to debulk only the intrapelvic portion of the mass, as it was felt to contribute to most of his symptoms. The case was reviewed with our vascular surgery colleagues who were available during the procedure.

In December 2019, the patient underwent debulking of the pseudotumor using the lateral window of the ilioinguinal approach. The anterior abdominal musculature was reflected medially off the iliac wing to expose an encapsulated mass adjacent to the iliacus muscle. This was incised, and more than $1 \mathrm{~L}$ of thick, blood-tinged debris was evacuated (Fig. 4). The acetabular component was palpable

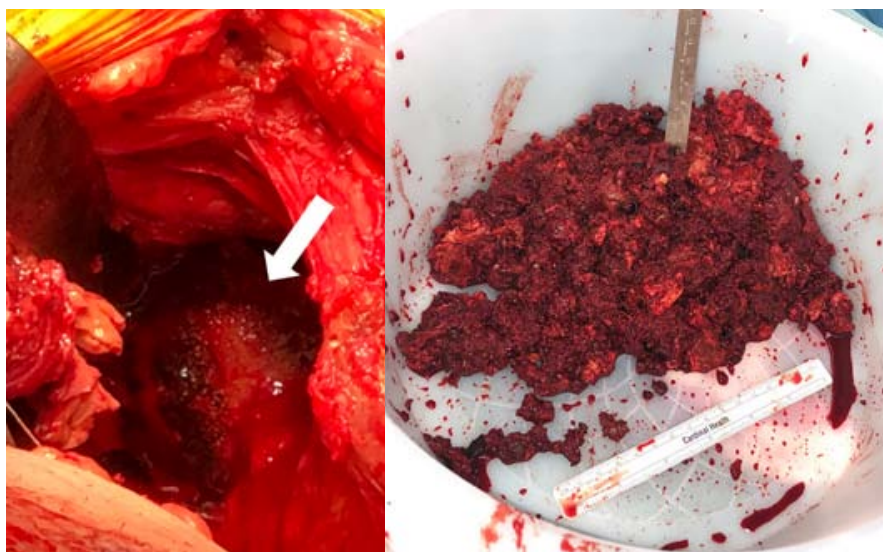

Figure 4: Intraoperative photograph taken through the lateral window demonstrating the porous coated shell visible through the inner table (white arrow) after debulking of the intrapelvic pseudotumor (Fig. 4-A). Clinical photograph of solid debris evacuated from within the fibrous wall of the mass (Fig. 4-B).
Figure 3: Preoperative anteroposterior pelvis radiograph (Fig. 3-A) and frog-leg lateral radiograph (Fig. 3-B). There is extensive osteolysis involving both the proximal femur (demarcated in white brackets) and acetabulum on the right with less severe osteolysis on the left. There is complete destruction of the right superior pubic ramus (red arrows). There is an intact superior rim of the right acetabulum without obvious component loosening or migration.

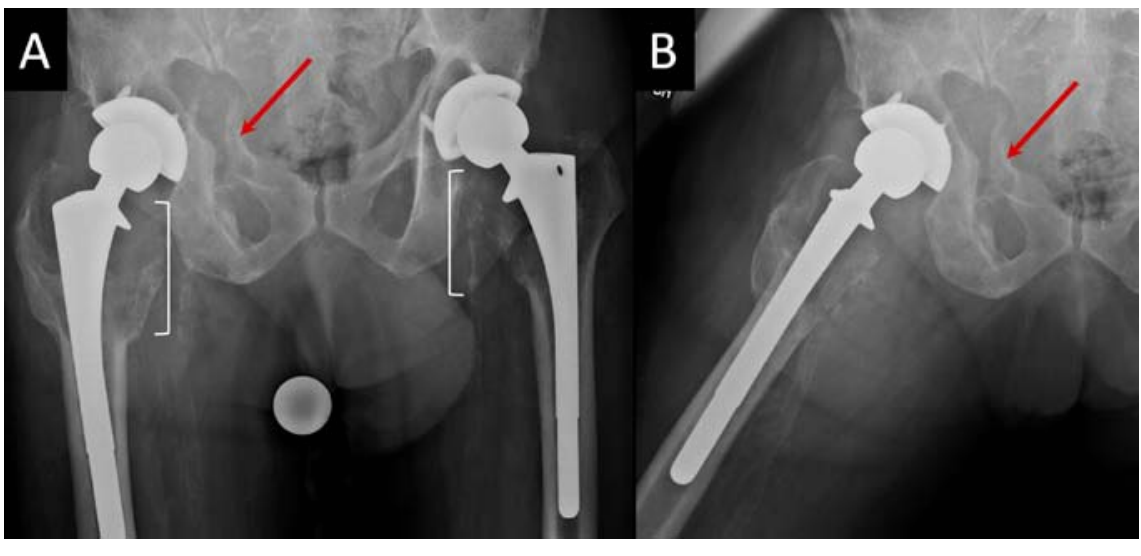




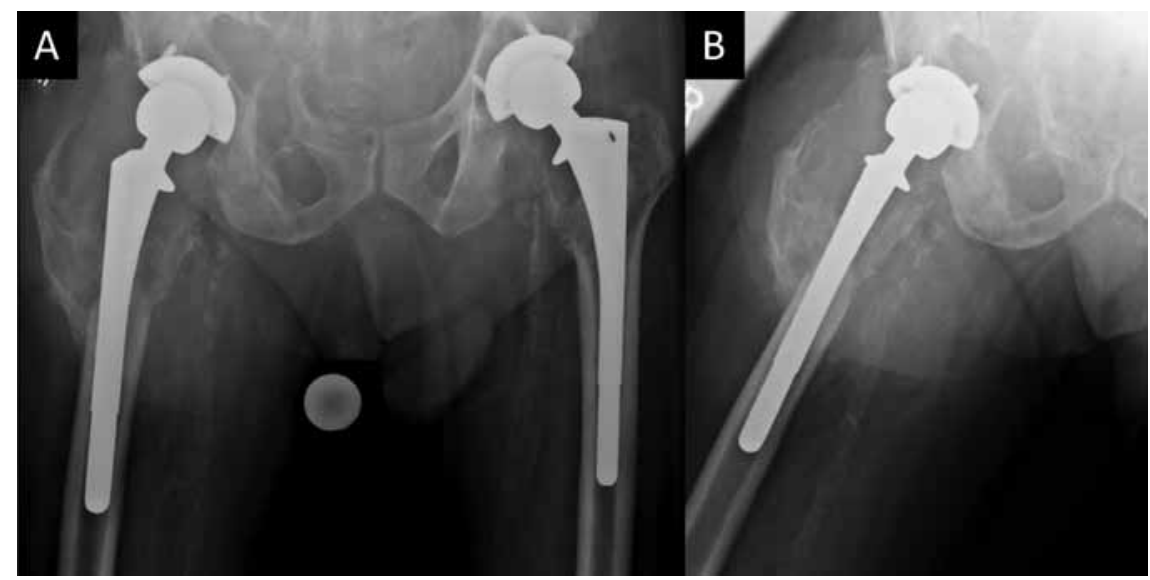

Figure 5: One-year postoperative anteroposterior pelvis radiograph (Fig. 5-A) and frogleg lateral radiograph (Fig. 5-B).

through the cystic cavity and noted to be stable and wellfixed to bone. Due to the thickness of the debris, it was not possible to express further debris from within the leg. The patient had an uneventful recovery and was discharged to a rehabilitation facility.

One year postoperatively, the patient reported no pain or subjective limp, and was very pleased with the results of his surgery. His swelling had resolved, paresthesias were improved, and he was able to sit comfortably. He continued to use a walker for ambulation. Repeat radiographs demonstrated stable THA components in comparison with preoperative films (Fig. 5). He requested to defer any further operative treatment, unless his extrapelvic symptoms worsened.

\section{Discussion}

Pseudotumor is an uncommon complication of THA, and the true prevalence is unknown $[\underline{4}, \underline{6}]$. In a meta-analysis, Wiley et al. reported a $0.6 \%$ estimated incidence of pseudotumor after MoM THA or resurfacing arthroplasty [12]. Higher prevalence has been reported in asymptomatic patients and after prolonged follow-up, suggesting growth of pseudotumors over time [13-16]. The rate of revision THA due to symptomatic pseudotumor has been reported to be $0.5 \%$ in non-MoM THAs and 2- to 3-fold higher in MoM THA $[\underline{6}, \underline{7}, \underline{12}, \underline{16}, \underline{17}]$. Intrapelvic masses associated with a THA are rare, and have been reported in roughly 30 published cases [18-49]. Pseudotumors associated with THA may be asymptomatic, and identification may occur during routine investigations for another reason. While unexplained pain is typically the presenting symptom, unilateral limb swelling [다-27, 29, $\underline{45}]$, sciatic nerve neuropathy [21] , femoral nerve neuropathy $[\underline{28}, \underline{30}, \underline{31}]$, venous thrombosis [ $\underline{32}-\underline{35}]$, and ureteral obstruction $[\underline{36}, \underline{37}]$ have been reported in several case reports.

While the observed differences in biologic response to prosthetic debris vary between patients, particles of all types of metals, polyethylene, and ceramic debris have been shown to induce a biologic response and initiate osteolysis [무]. Our patient presented 27 years after his index THA and 9 years after his revision THA with extensive osteolysis and pseudotumor formation, which we suspect developed in response to wear debris related to his index THA liner. The accelerated wear, risk of osteolysis, and early failures of Hylamer liners, which were introduced in the early 1990s, are well-documented in the literature [51-54]. However, there is limited long-term follow-up information available on patients who have received this bearing surface. This data is important and an additional unique aspect of this patient's case worth highlighting.

The authors acknowledge several limitations associated with the perioperative workup for this case. The patient had undergone an extensive preoperative workup at several outside facilities prior to his evaluation in our office for definitive treatment, and thus a component of the decision making in this case relied on the quality of his medical records. Although the patient's clinical presentation, symptoms, outside laboratory studies, and previous biopsy results were not suggestive of a prosthetic joint infection, a full infectious workup would have ideally been performed at our institution. Additionally, while his pseudotumor and osteolysis were felt to be related to polyethylene wear, rather than metallosis, obtaining serum metal ion levels (cobalt and chromium) would have been prudent. Finally, unfortunately histological slides are discarded after a holding period at our institution and were not available to for image review of this case. Retaining a digital collection of intra-operative soft tissue specimens collected by institutions would be of value for patient care and retrospective case review.

Interestingly, our patient developed symptoms after previously undergoing a right sided lumbar spine decompression and right lower extremity vascular bypass. To our knowledge, this is the first case report to describe a pseudotumor in a patient with a history of operative spine and vascular surgery for symptoms in the ipsilateral extremity. The case presented also represents one of the largest pseudotumors documented in the literature.

The treatment decision for addressing symptomatic pseudotumors is challenging and options include aspiration, removal of the source of wear debris by component 
revision or liner exchange, or resection with or without revision THA $[\underline{3}, \underline{4}, \underline{26}, \underline{39}]$. Bolognesi et al. provided a framework for the evaluation and treatment of patient with MoM THAs, and a recent consensus statement from the AAOS and AAHKS provides guidance for the evaluation and treatment of ALTR in metal-on-polyethylene THAs [ㄹ,, ]. However, there is a paucity of data available to guide the evaluation and management of ALTR in patients who have previously been revised. We are aware of only three previous reports documenting enlargement or recurrence of a pseudotumor after revision THA and removal of the source of wear debris $[\underline{31}, \underline{55}, \underline{56}]$. Revision THA for pseudotumor is recognized to have poor outcomes and high complication rates due to bone loss and periarticular soft tissue damage compromising stability [ $\underline{57}-\underline{59}]$.

To the best of our knowledge, there has been only one case reporting management of an intrapelvic pseudotumor with excision only [르] . However, in this case the patient refused a revision surgery and follow-up was not reported [르] . Most studies reporting intrapelvic pseudotumors document resection of the mass during revision THA, rather than for symptomatic treatment. In our case, debulking of the solid intrapelvic portion of the mass was performed to relieve compressive effects taking into careful consideration the patient's goals and functional demands. The decision to retain the acetabular cup was based on clinical and radiographic evaluation. The current case documents the potential for symptomatic relief after debulking of an intrapelvic pseudotumor.

In conclusion, clinicians need to be aware of pseudotumors as a differential diagnosis in patients with a history of THA who present with unilateral limb swelling, pain, or neuropathic symptoms. A multidisciplinary approach is advocated with close communication between musculoskeletal radiologists, musculoskeletal oncologists, pathologists, orthopaedic surgeons, and vascular surgeons. Debulking of the solid intrapelvic mass is a potential treatment option after revision THA in the setting of well-fixed components. Continued, long-term observation is warranted as re-accumulation of debris and recurrence of symptoms may occur.

\section{References}

1. McGrory BJ, Jacobs JJ, Kwon YM, Fillingham Y. Standardizing terms for tribocorrosion-associated adverse local tissue reaction in total hip arthroplasty. Arthroplast Today 2020;6:196-200. https://doi.org/10.1016/j.artd.2020.01.008.

2. Kwon Y-M, della Valle CJ, Lombardi A v, Garbuz DS, Berry DJ, Jacobs JJ. Risk Stratification Algorithm for Management of Head-Neck Taper Tribocorrosion in Patients with Metal-on-Polyethylene Total Hip Arthroplasty: Consensus Statement of the American Association of Hip and Knee Surgeons, the American Academy of Orthopaedic Surgeons, and The Hip Society. J Bone Joint Surg Am 2021;103:e1-9. https://doi.org/10.2106/JBJS.20.01837.

3. Plummer DR, Berger RA, Paprosky WG, Sporer SM, Jacobs JJ, della Valle CJ. Diagnosis and Management of Adverse Local Tissue Reactions Secondary to Corrosion at the Head-Neck Junction in Patients With Metal on Polyethylene Bearings.
J Arthroplasty 2016;31:264-8. https://doi.org/10.1016/j.arth.2015.07.039.

4. Daniel J, Holland J, Quigley L, Sprague S, Bhandari M. Pseudotumors associated with total hip arthroplasty. J Bone Joint Surg Am 2012;94:86-93. https://doi. org/10.2106/JBJS.J.01612.

5. Hall DJ, Pourzal R, Jacobs JJ. What Surgeons Need to Know About Adverse Local Tissue Reaction in Total Hip Arthroplasty. J Arthroplasty 2020;35:S55-9. https:// doi.org/10.1016/j.arth.2020.01.016.

6. Pandit H, Glyn-Jones S, Mclardy-Smith P, Gundle R, Whitwell D, Gibbons CLM, et al. Pseudotumours associated with metal-on-metal hip resurfacings. J Bone Joint Surg Br 2008;90:847-51. https://doi.org/10.1302/0301-620X.90B7.

7. Bolognesi MP, Ledford CK. Metal-on-Metal Total Hip Arthroplasty: Patient Evaluation and Treatment. J Am Acad Orthop Surg 2015;23:724-31. https://doi. org/10.5435/JAAOS-D-14-00183.

8. Yoshihara Y, Shiromoto Y, Tatsumi M, Hirano M, Kawano T, Arino H, et al. Backflow from a Metallosis-Induced Intrapelvic Mass into a Revision Hip Arthroplasty. JBJS Case Connector 2013;3:e66. https://doi.org/10.2106/jbjs.cc.1.00201.

9. Swiontkowski M, Resnick L. Pseudotumors After Non-MoM Hip Replacements. JBJS Case Connector 2014;4:e27. https://doi.org/10.2106/jbjs.cc.n.00023.

10. Hjorth MH, Mechlenburg I, Soballe K, Roemer L, Jakobsen SS, Stilling M. Higher Prevalence of Mixed or Solid Pseudotumors in Metal-on-Polyethylene Total Hip Arthroplasty Compared With Metal-on-Metal Total Hip Arthroplasty and Resurfacing Hip Arthroplasty. J Arthroplasty 2018;33:2279-86. https://doi. org/10.1016/j.arth.2018.02.011.

11. Clyburn TA. Pseudotumor in Metal-on-Polyethylene Total Hip Arthroplasty. Reconstructive Review 2013:18-21.

12. Wiley KF, Ding K, Stoner JA, Teague DC, Yousuf KM. Incidence of pseudotumor and acute lymphocytic vasculitis associated lesion (ALVAL) reactions in metal-on-metal hip articulations: A meta-analysis. J Arthroplasty 2013;28:1238-45. https://doi.org/10.1016/j.arth.2013.03.027.

13. Williams DH, Greidanus N v., Masri BA, Duncan CP, Garbuz DS. Prevalence of pseudotumor in asymptomatic patients after metal-on-metal hip arthroplasty. J Bone Joint Surg Am 2011;93:2164-71. https://doi.org/10.2106/JBJS.J.01884.

14. Weber MA, Snyder MJ, Workman KK, Sims MM, Smith CN, Kumar D, et al. Comparison of Asymptomatic and Symptomatic Adverse Local Tissue Reaction in Patients With Head-Neck Taper Corrosion. J Arthroplasty 2020. https://doi. org/10.1016/j.arth.2020.09.014.

15. Almousa SA, Greidanus N v., Masri BA, Duncan CP, Garbuz DS. The natural history of inflammatory pseudotumors in asymptomatic patients after metal-onmetal hip arthroplasty. Clin Orthop Relat Res 2013;471:3814-21. https://doi. org/10.1007/s11999-013-2944-4.

16. Persson A, Eisler T, Bodén H, Krupic F, Sköldenberg O, Muren O. Revision for symptomatic pseudotumor after primary metal-on-polyethylene total hip arthroplasty with a standard femoral stem. J Bone Joint Surg Am 2018;100:942-9. https://doi.org/10.2106/JBJS.17.00616.

17. Bosker BH, Ettema HB, van Rossum M, Boomsma MF, Kollen BJ, Maas M, et al. Pseudotumor formation and serum ions after large head metal-on-metal stemmed total hip replacement. Risk factors, time course and revisions in 706 hips. Arch Orthop Trauma Surg 2015;135:417-25. https://doi.org/10.1007/s00402-015-2165-2.

18. Wang J-W, Lin C-C, Wang W. Pelvic Mass Caused by Polyethylene Wear After Uncemented Total Hip Arthroplasty Case Report. J Arthroplasty 1996;11:626-8.

19. Hattrup S, Richard B, Gaffey T, Stanhope R. Pelvic mass causing vesical compression after total hip arthroplasty. Case report. Clin Orthop Relat Res 1988;227:184 9.

20. Shilt JS, Rozencwaig R, Wilson MR. Pelvic Mass Secondary to Polyethylene and Titanium Alloy Wear Debris Resulting in Recurrent Deep Vein Thrombosis. J Arthroplasty 1997;12:946-9.

21. Fischer SR, Christ DJ, Roehr BA. Sciatic Neuropathy Secondary to Total Hip Arthroplasty Wear Debris. J Arthroplasty 1999;14:771-4. https://doi.org/10.1016/ s0883-5403(99)90237-1.

22. Jeanrot C, Ouaknine M, Anract P, Forest M, Tomeno B. Massive pelvic and femoral pseudotumoral osteolysis secondary to an uncemented total hip arthroplasty. Int Orthop 1999;23:37-40. https://doi.org/10.1007/s002640050300.

23. Mak KH, Wong TK, Poddar NC. Wear debris from total hip arthroplasty presenting as an intrapelvic mass. J Arthroplasty 2001;16:674-6. https://doi.org/10.1054/ arth.2001.23726.

24. Nazarian DG, Zeni JA. Management of a pelvic mass following a worn uncemented total hip arthroplasty. J Arthroplasty 2012;27:323.e17-323.e20. https://doi. org/10.1016/j.arth.2011.03.023.

25. Allen Butler R, Barrack RL. Total Hip Wear Debris Presenting as Lower Extremity Swelling. A Report of Two Cases. J Bone Joint Surg Am 2004;86:142-5.

26. Lencioni A, Ellis B, Dean CS, Lendrum J, Hogan CA. Metal-on-metal total hip arthroplasty adverse local tissue reaction with intermittent unilateral vascular claudication. Arthroplast Today 2019;5:389-93. https://doi.org/10.1016/j. 


\section{artd.2019.08.012.}

27. Grote CW, Cowan PC, Anderson DW, Templeton KJ. Pseudotumor from Metal-on-Metal Total Hip Arthroplasty Causing Unilateral Leg Edema: Case Presentation and Literature Review. Biores Open Access 2018;7:33-8. https://doi. org/10.1089/biores.2017.0035.

28. Harvie P, Giele H, Ansorge O, Ostlere S, Gibbons M, Whitwell D. The treatment of femoral neuropathy due to pseudotumour caused by metal-on-metal resurfacing arthroplasty. Hip Int 2008;18:313-20.

29. Kawakita K, Shibanuma N, Tei K, Nishiyama T, Kuroda R, Kurosaka M. Leg Edema Due to a Mass in the Pelvis After a Large-Diameter Metal-On-Metal Total Hip Arthroplasty. J Arthroplasty 2013;28:197.e1-197.e4. https://doi.org/10.1016/j. arth.2012.04.016.

30. Fokter SK, Repše-Fokter A, Takač I. Case report: Femoral neuropathy secondary to total hip arthroplasty wear debris. Clin Orthop Relat Res 2009;467:3032-5. https://doi.org/10.1007/s11999-009-0894-7.

31. Leung P, Kudrna JC. Growth of an intrapelvic pseudotumor associated with a metal-on-metal total hip arthroplasty after revision arthroplasty causing a femoral nerve neuropathy. Arthroplast Today 2016;2:105-9. https://doi.org/10.1016/j. artd.2016.07.001.

32. Abdel-Hamid H, Miles J, Carrington RWJ, Hart A, Loh A, Skinner JA. Combined Vascular and Orthopaedic Approach for a Pseudotumor Causing Deep Vein Thrombosis after Metal-on-Metal Hip Resurfacing Arthroplasty. Case Rep Orthop 2015;2015:1-4. https://doi.org/10.1155/2015/926263.

33. Parfitt DJ, Wood SN, Chick CM, Lewis P, Rashid MH, Evans AR. Common Femoral Vein Thrombosis Caused By a Metal-On-Metal Hip Arthroplasty-Related Pseudotumor. J Arthroplasty 2012;27:1581.e9-1581.e11. https://doi.org/10.1016/j. arth.2012.01.024.

34. Memon AR, Galbraith JG, Harty JA, Gul R. Inflammatory Pseudotumor Causing Deep Vein Thrombosis After Metal-On-Metal Hip Resurfacing Arthroplasty. J Arthroplasty 2013;28:197.e9-197.e12. https://doi.org/10.1016/j.arth.2012.02.014.

35. Maurer-Ertl W, Friesenbichler J, Liegl-Atzwanger B, Kuerzl G, Windhager R, Leithner A. Noninflammatory pseudotumor simulating venous thrombosis after metal-on-metal hip resurfacing. Orthopedics 2011;34:e678-681. https://doi org/10.3928/01477447-20110826-32.

36. Hananouchi T, Saito M, Nakamura N, Yamamoto T, Yonenobu K. Huge pelvic mass secondary to wear debris causing ureteral obstruction. J Arthroplasty 2005;20:946-9. https://doi.org/10.1016/j.arth.2004.11.005.

37. Kilicoglu ZG, Kilicoglu OI, Simsek MM. Total hip arthroplasty-related pelvic pseudotumor: Unusual presentation with hydronephrosis. Acta Orthop Traumatol Turc 2016;50:470-2. https://doi.org/10.1016/j.aott.2016.05.001.

38. Regis D, Sandri A, Costa A, Mazzilli G, Bartolozzi P. Recurrent femoral deep vein thrombosis: Rare complication of a pelvic mass induced by polyethylene wear debris following total hip arthroplasty. A case report. Thromb Res 2008;121. https:// doi.org/10.1016/j.thromres.2007.05.024.

39. Leigh W, O'Grady P, Lawson EM, Hung NA, Theis JC, Matheson J. Pelvic Pseudotumor. An Unusual Presentation of an Extra-Articular Granuloma in a Well-Fixed Total Hip Arthroplasty. J Arthroplasty 2008;23:934-8. https://doi. org/10.1016/j.arth.2007.08.003.

40. Lin KHB, Lo NN. Failure of Polyethylene in Total Hip Arthroplasty Presenting as a Pelvic Mass. J Arthroplasty 2009;24:1144.e13-1144.e15. https://doi. org/10.1016/j.arth.2008.06.029.

41. Adelman S, Urquhart A, Biermann J, Freiberg A. Polyethylene wear debris presenting as a retroperitoneal tumor. Surgery 1998;123:111-2.

42. Hisatome T, Yasunaga Y, Takahashi K. Hidden Intrapelvic Granulomatous Lesions Associated with Total Hip Arthroplasty: A Report of Two Cases. J Bone Joint Surg Am 2003;85:708-10.

43. Madan S, Jowett R, Goodwin M. Recurrent intrapelvic cyst complicating metal-onmetal cemented total hip arthroplasty. Arch Orthop Trauma Surg 2000;120:50810.

44. Kohn D, Pape D. Extensive Intrapelvic Granuloma Formation Caused by Ceramic Fragments After Revision Total Hip Arthroplasty. J Arthroplasty 2007;22:293-6. https://doi.org/10.1016/j.arth.2006.01.030.

45. Tamaki Y, Goto T, Tsutsui T, Takasago T, Wada K, Sairyo K. Compression of the Femoral Vessels by a Pseudotumor after Metal-on-Metal Total Hip Arthroplasty. Case Rep Orthop 2017;2017:1-5. https://doi.org/10.1155/2017/2594902.

46. McPherson, M.D., FACS E, Dipane, BA M, Sherif, MD S. Massive Pseudotumor in a $28 \mathrm{~mm}$ Ceramic-Polyethylene Revision THA: A Case Report. Reconstructive Review 2014;4:11-7. https://doi.org/10.15438/rr.v4i1.53.

47. Serrano PM, Rodrigues C, S. Silva M, Coelho R, Cardoso P, Oliveira V. Pseudotumor complicating a well-fixed ceramic-on-polyethylene total hip arthroplasty. Clin Case Rep 2018;6:1756-60. https://doi.org/10.1002/ccr3.1720.

48. Svensson O, Mathiesen EB, Reinholt FP, Blomgren G. Formation of a fulminan soft-tissue pseudotumor after uncemented hip arthroplasty. A case report. J Bone
Joint Surg Am 1988;70:1238-42.

49. Murgatroyd SE. Pseudotumor Presenting as a Pelvic Mass: A Complication of Eccentric Wear of a Metal on Polyethylene Hip Arthroplasty. Journal of Arthroplasty 2012;27:820.e1-820.e4. https://doi.org/10.1016/j.arth.2011.09.008.

50. Ollivere B, Wimhurst JA, M. Clark I, Donell ST. Current concepts in osteolysis. J Bone Joint Surg Br 2012;94-B. https://doi.org/10.1302/0301-620X.94B1.28047.

51. Bradley Vaughn BK, Dameron TB, Bauer TW, Mochida Y, Akisue T, Eberle RW, et al. Early Osteolysis Following Total Hip Arthroplasty with Use of a Hylamer Liner in Combination with a Modular Ceramic Femoral Head. A case report. J Bone Joint Surg Am 1999;81:1446-9.

52. Livingston BJ, Chmell MJ, Spector M, Poss R. Complications of total hip arthroplasty associated with the use of an acetabular component with a Hylamer liner. J Bone Joint Surg Am 1997;79:1529-38.

53. Stea S, Antonietti B, Baruffaldi F, Visentin M, Bordini B, Sudanese A, et al. Behavior of Hylamer polyethylene in hip arthroplasty: Comparison of two gamma sterilization techniques. Int Orthop 2006;30:35-8. https://doi.org/10.1007/ s00264-005-0022-6.

54. Huddleston JI, Harris AHS, Atienza CA, Woolson ST. Hylamer vs Conventional Polyethylene in Primary Total Hip Arthroplasty: A Long-Term Case-Control Study of Wear Rates and Osteolysis. J Arthroplasty 2010;25:203-7. https://doi. org/10.1016/j.arth.2009.02.006.

55. Desai BR, Sumarriva GE, Chimento GF. Pseudotumor recurrence in a post-revision total hip arthroplasty with stem neck modularity: A case report. World J Orthop 2020;11:116-22. https://doi.org/10.5312/wjo.v11.i2.116.

56. Kwon YM, Rossi D, MacAuliffe J, Peng Y, Arauz P. Risk Factors Associated With Early Complications of Revision Surgery for Head-Neck Taper Corrosion in Metal-on-Polyethylene Total Hip Arthroplasty. J Arthroplasty 2018;33:3231-7. https://doi.org/10.1016/i.arth.2018.05.046.

57. Waterson HB, Whitehouse MR, Greidanus N v, Garbuz DS, Masri BA, Duncan CP. Revision for adverse local tissue reaction following metal-on-polyethylene total hip arthroplasty is associated with a high risk of early major complications. Bone Joint J 2018:720-4. https://doi.org/10.1302/0301-620X.100B6.

58. Bonner B, Arauz P, Klemt C, Kwon YM. Outcome of Re-Revision Surgery for Adverse Local Tissue Reaction in Metal-on-Polyethylene and Metal-on-Metal Total Hip Arthroplasty. J Arthroplasty 2020;35:S284-8. https://doi.org/10.1016/j. arth.2020.02.006.

59. Grammatopoulos G, Pandit H, Kwon Y-M, Gundle R, Mclardy-Smith P, Beard DJ, et al. Hip resurfacings revised for inflammatory pseudotumour have a poor outcome. J Bone Joint Surg Br 2009;91:1019-24. https://doi.org/10.1302/0301620X.91B8

\section{SUBMISSION HISTORY}

Submitted: June 28, 2021

Reviewed: September 10, 2021

Revised: September 15, 2021

Accepted: October 1, 2021

Published: October 12, 2021

\section{AUTHOR AFFILIATIONS}

1 Dr Matthew C. Sweet, MD

Department of Orthopaedic Surgery, Western Michigan University Homer Stryker M.D. School of Medicine, Kalamazoo, MI

2 Tyler Snoap, MD; Bernard A. Roehr, MD; Jason W. Roberts, MD Bronson Methodist Hospital, Kalamazoo, MI

(Direct inquires to Matthew Sweet, Matthew.Sweet@med.wmich.edu)

AUTHOR DISCLOSURES

- The authors declare that there is no conflict of interest in connection with this submitted article.

\section{COPYRIGHT \& OPEN ACCESS}

(C) 2021 Sweet, Snoap, Roehr, Roberts. All rights reserved. Authors retain copyright and grant the journal right of first publication with the work. Reconstructive Review is an open access publication and follows the Creative Commons Attribution-NonCommercial CC BY-NC. This license allows anyone to download works, build upon the material, and share them with others for non-commercial purposes as long as they credit the senior author, Reconstructive Review, and the Joint Implant Surgery \& Research Foundation (JISRF). An example credit would be: "Courtesy of (senior author's name), Reconstructive Review, JISRF, Chagrin Falls, Ohio". 